\title{
MEMBANGKITKAN KOMPETENSI IR 4.0. PADA GURU SEKOLAH DASAR MELALUI PELATIHAN SINGKAT PEMANFAATAN DIGITAL
}

\author{
Astri Dwi Jayanti S. \\ Universitas Terbuka \\ e-mail: astri@ecampus.ut.ac.id
}

\begin{abstract}
The digital age drives change in many sectors of life. In this age, correspondence between two continents happens immediately, and knowledge is exchanged and expended rapidly. Teachers as a focal figure in the realm of instruction are required to redress and even decipher these progressions as a methods for facilitating students to secure the 21st century capabilities. In any case, actually, a large number of teachers are hesitant to connect with these changes, particularly those related with the utilization of innovation in instruction and learning. In some developing countries, for example, Indonesia, a great deal of teachers are frustrated with the digital gap, less expertise in applying technology, limited supporting infrastructure, and students' age variation. This article investigates the impact of short training on digital technology use in education to 29 primary teachers in Jakarta, Indonesia. The training course includes the introduction of the materials on digital learning, followed by assignment of looking for learning resources on the web, and an essay writing as the assessment to finish of the program. The observations and interviews with 7 respondents showed that the activity of the training improved the teachers' digital literacy, especially in the utilization of technology in education.
\end{abstract}

Keywords: Digital age, Digital literacy, Primary teacher, Industry Revolution 4.0

\begin{abstract}
Abstrak: Era digital menyebabkan perubahan yang signifikan disetiap lini kehidupan. Pada masa ini komunikasi antar dua benua terjadi seketika, realitas dimodifikasi dan dikonsumsi secara cepat. Guru sebagai sosok sentral dalam dunia pendidikan dituntut untuk mengimbangi bahkan menerjemahkan perubahan tersebut sebagai sarana menghasilkan peserta didik yang memiliki kompetensi abad 21. Namun pada kenyataanya banyak guru yang segan bersinggungan dengan perubahan ini, khususnya yang berkaitan dengan pemanfaatan teknologi dalam pembelajaran. Di beberapa Negara berkembang seperti Indonesia banyak guru yang frustasi karena adanya jurang digital yakni kurang terampil dalam mangaplikasikan teknologi, terbatasnya sarana-prasarana yang mendukung, dan adanya perbedaan usia dengan para peserta didik. Artikel ini mengeksplorasi implikasi dari pelatihan dan pengembangan keterampilan menggunakan teknologi digital yang diberikan kepada 29 guru sekolah dasar di Jakarta, Indonesia. Pelatihan dilaksanakan selama 2 hari pada bulan Juni 2019, diawali dengan penyajian materi, praktik mencari sumber pembelajaran melalui internet kemudian dilanjutkan dengan pemberian evaluasi berupa soal uraian. Berdasarkan hasil observasi dan wawancara dengan 7 orang guru diketahui bahwa pelatihan yang diberikan berdayaguna dalam meningkatkan literasi digital guru untuk memanfaatkan teknologi dalam pendidikan.
\end{abstract}

Kata kunci: Era digital, Literasi digital, Guru Sekolah Dasar, Revolusi Industri 4.0 


\section{PENDAHULUAN}

Saat ini dunia telah memasuki era revolusi industri 4.0 yang populer dengan sebutan revolusi digital. Pada era ini teknologi komputer dan jaringan internet secara masif digunakan di berbagai bidang pekerjaan. Pemanfaatan teknologi digital ini bermula dari industri manufaktur kemudian merambah pada bidang lainnya yakni bisnis, agrikultur, keamanan serta pendidikan. Hal ini bermakna bahwa teknologi informasi menjadi sangat fundamental dalam keberlangsungan hidup manusia. Adapun perkara kesiapan Indonesia dalam menghadapi era disrupsi ini terletak pada terbatasnya kapabilitas sumber daya manusia (SDM) mengutilisasi teknologi dalam bidang yang digeluti.

Ihwal pengembangan kemampuan SDM terhadap teknologi erat kaitannya dengan pendidikan sepanjang hayat, baik yang bersinggungan dengan kurikulum maupun sistem pengajaran. Dalam hal ini guru sebagai pendidik, fasilitator, dan agen transfer teknologi menjadi tumpuan dalam menumbuhkan kompetensi era 21 yakni creativity, critical thinking, communication and collaboration/4Cs (Bellanca, 2010) kepada peserta didik. Tanggung jawab besar ini mendesak para guru untuk menguasai penerapan teknologi dalam pembelajaran dan pengajaran. Alih-alih memupuk 4Cs, banyak guru menolak penggunaan teknologi dalam proses pembelajaran di kelas. Mereka gamang dengan adanya kesenjangan digital yakni keterampilan yang dimiliki dengan kemajuan teknologi yang cepat, serta kesenjangan antara keterampilan guru dan peserta didik (Guemide \& Benachaiba, 2012). Sehingga para guru bertahan dengan pengajaran tradisional dan seminim mungkin menerapkan teknologi (Labbas \& Shaban, 2013).

Kesenjangan digital ini dialami pula oleh guru-guru di sebagian besar daerah di Indonesia. Tercatat dalam survey Badan Pusat Statistik (BPS) terhadap 4.014 sekolah yang tersebar di 34 provinsi ditemukan bahwa proporsi guru yang mempunyai kualifikasi di bidang TIK untuk semua jenjang pendidikan hanya sebesar 10,10 persen (Sutarsih \& Hasyyati, 2018). Sedangkan proporsi peserta didik yang mengakses internet di sekolah untuk semua jenjang pendidikan terekam sebesar 33,67 persen. Perbedaan kriteria data dan proporsi jumlah pengguna teknologi informasi, tidak bisa menutupi terdapatnya kesenjangan keterampilan menggunakan dan mengakses teknologi informasi yang dimiliki oleh guru dan peserta didik.

Terlepas kesenjangan digital yang dialami oleh banyak guru di Indonesia, didapati sekolah-sekolah yang secara gencar meningkatkan pemanfaatan teknologi informasi dalam proses pembelajaran di sekolah. Seperti halnya SMA Muhammadiyah Tarakan, terdapat 27 orang guru berupaya untuk menggunakan laptop/komputer untuk mempresentasikan materi pelajaran, dua diantaranya menggunakan internet dan jejaring sosial untuk dalam mencari sumber materi yang dibutuhkan (Husain, 2014). Begitu juga guru-guru dari SMPN 2 Kawali-Citeurep yang secara terbuka menerima pelatihan mengenai pemanfaatan ICT dalam proses pembelajaran dari para dosen Universitas Padjajaran (Budiana, Sjafirah, \& Bakti, 2015). Sama halnya dengan salah satu guru matematika di SDN Kampelan Blora yang bersedia bekerjasama dengan mahasiswa UNSA untuk mengembangkan media pembelajaran interaktif matematika berbasis teknologi untuk kelas IV SD (Wibowo, 2013). 
Bagi sekolah yang memiliki guru-guru yang telah siap dengan komptensi di bidang ICT seperti yang telah dideskripsikan sebelumnya perlu adanya peningkatan kompetensi pendukung yakni keterampilan literasi digital. Dalam pengertiannya gerakan literasi lebih dari sekedar membaca dan menulis tetapi juga meliputi kemampuan berpikir kritis dalam mengolah informasi yang telah dibaca atau yang akan ditulis (Teguh, 2017). Sementara literasi digital adalah tidak terbatas pada kompetensi teknis penggunaan teknologi dalam mencari informasi, namun keterampilan dalam membaca, memahami, mengkritisi dan menyajikan sebuah pengetahuan/informasi yang diperoleh melalui perangkat teknologi beserta jaringan internet yang mendukungnya (Kurnianingsih, Rosini, \& Ismayati, 2017). Menurut Buckingham literasi digital tidak sesederhana memahami teknologi dan informasi sebagai perangkat pendukung, namun lebih kepada koneksi yang efektif, antara pengalaman guru/peserta didik dalam menggunakan teknologi informasi didalam dan di luar kelas (Buckingham, 2015). Dengan demikian dapat disimpulkan bahwa literasi digital merupakan proses dan kemampuan guru/perserta didik dalam mengolah dan memaparkan informasi dari/melalui teknologi digital yang diasosiasikan dengan pengalaman dari dalam dan luar kelas.

Berdasarkan latar belakang tersebut, peneliti merancang sebuah rangkaian pelatihan dan evaluasi pendukung untuk mengembangkan kompetensi literasi digital guru sekolah dasar. Tujuannya adalah untuk mengetahui pengaruh pelatihan dan evaluasi yang dirancang terhadap pemahamanan guru dalam hal literasi digital, yang ditunjukkan melalui keterampilan guru dalam memproses dan menyajikan pengetahuan melalui teknologi informasi.

\section{METODE PENELITIAN}

Penelitian ini menggunakan metode penelitian kualitatif sebagai untuk memahami perilaku guru saat mengikuti pelatihan pengembangan keterampilan literasi digital (Mertens, 2014). Peneliti melakukan observasi selama pelatihan berlangsung diantara merekam perilaku para guru saat: (1) pemberian materi keterampilan literasi digital, (2) melakukan latihan pemanfaatan literasi digital, (3) mengisi form evaluasi materi dan pelatihan. Wawancara mendalam merupakan instrumen dalam penelitian kualitatif yang membantu peneliti dalam memahami pengalaman unik informan dari sudut pandang mereka. Guru sebagai pemberi informasi utama dalam penelitian ini diwawancara agar peneliti bisa memahami manfaat dari pelatihan yang telah dilakukan, terutama mengenai proses pemahaman dan implementasi pemanfaatan literasi digital.

Data observasi dikumpulkan sejak diadakannya pelatihan pemanfaatan literasi digital yang dihadiri oleh seluruh 29 guru SDN Warakas 07 Jakarta Utara. Sedangkan data wawancara dihimpun peneliti terhadap 7 guru, empat diantaranya adalah guru kelas sedangkan 3 lainnya merupakan guru bidang studi Bahasa Inggris, Pendidikan Agama Islam dan Olah Raga. Kedua data tersebut di transkrip kemudian dilakukan pengkodean pada masing-masing pernyataan informan. Proses pengkodean ini berdasarkan proposisi retorik dengan melihat kesetaraan kata dari berbagai variasi pernyataan yang diungkapkan oleh informan (Huberman \& Miles, 2002). Kemudian peneliti menyusun kategori dari serangkaian pola kode yang telah dibuat (Strauss \& Corbin, 1997). 
Pelatihan dilakukan 2 hari dengan rangkaian sebagai berikut: (1) Pengenalan Era Revolusi Industri 4.0, (2) penyajian video motivasi mengenai pentingnya hubungan yang baik dengan peserta didik, (3) pengenalan dan implementasi teknis sumber-sumber informasi dan pengetahuan digital, (4) evaluasi materi dan pemaparan pelatihan. Setelahnya pengumpulan data wawancara dilakukan pada dua hari yang berbeda disesuaikan dengan waktu senggang yang dimiliki para guru.

\section{TEMUAN DAN PEMBAHASAN}

Temuan dan diskusi pada penelitian ini difokuskan kepada implikasi dari pelaksanaan pelatihan mengenai pemanfaatan literasi digital pada guru sekolah dasar di SDN Warakas 07, Jakarta Utara. Melalui wawancara dengan 7 orang guru dan observasi yang dilakukan selama pelatihan berlangsung peneliti mengindikasikan bahwa para guru berhasil merefleksikan, memahami dan mempraktekkan pemanfaatan literasi digital. Pada bagian ini peneliti menjelaskan temuan tersebut dalam beberapa kategori berdasarkan materi yang diberikan saat pelatihan dan pertanyaan saat sesi wawancara.

\section{Memperdalam Jiwa Mengajar dan Mendidik}

Pada sesi awal dalam pelatihan, untuk memberikan landasan kependidikan, peneliti memutarkan video pertama mengenai pentingnya memiliki dan menetapkan impian dan tujuan hidup, dilanjutkan dengan praktek menyusun impian dan tujuan hidup. Video yang kedua mengenai menjadi guru yang menginspirasi dan menghargai hubungan yang terjalin dengan peserta didik. Kedua materi tersebut berhasil memotivasi para guru menjadi pendidik yang lebih baik dengan cara memperbaharui impian dan tujuan hidup terutama dalam merencanakan dan menyusun sasaran dalam pengajaran, serta senantiasa membangun interaksi yang erat dengan peserta didik.

P1.Q1. Saya sangat termotivasi melihat video yang diberikan saat pelatihan, ternyata berbeda orang yang punya rencana dan tidak punya rencana dalam hidup. Bapak A tidak menunda pekerjaan jadi, pekerjaan lancar, bisa bangun rumah dan jalan-jalan ke luar negeri. Berbeda dengan bapak B nggak ada rencana, pekerjaan tidak ada yang selesai.

P3.Q1. Kami diminta untuk menyusun target 5 dan 10 tahun ke depan sebagai pribadi, guru, peran dikeluarga dan di masyarakat. Kami jadi tahu bagaimana menentukan target, setiap rencana ditulis dengan lengkap dan detail. Jadi guru juga harus punya tujuan apa saja yang harus diajarkan ke ssiwa, metode dan alat apa yang digunakan.

P7.Q1. Video bu Rita bagus sekali, saya jadi semakin semangat untuk menjadi lebih baik. Penting sekali memiliki hubungan yang baik dengan anak murid. Kita harus selalu memotivasia murid kita agar mereka semangat dalam belajar dan berhasil. Rita juga cerita saat ibunya yang juga seorang guru meninggal dunia, banyak sekali 
yang datang di pemakaman. Begitulah kalau guru bisa dekat dengan

anak didiknya.

Temuan ini menguatkan penelitian sebelumnya bahwa motivasi mengajar para guru sangat mempengaruhi kinerja mereka baik saat mengajar maupun mengaktualisasikan diri (Sumantri, 2017). Karena itulah penting diadakannya rehcharging motivation melalui berbagai program kegiatan yang diadakan sekolah atau dinas pendidikan (Ahmadi, 2017).

\section{Meluaskan Wawasan Mengenai Era Revolusi Industri 4.0}

Pada sesi berikutnya peneliti mengajukan pertanyaan mengenai apa yang dimaksud dengan Era Revolusi Industi 4.0. Hanya beberapa guru yang telah mendengar konsep tersebut, dan sebagian besar belum memahaminya secara komprehensif. Setelah peneliti melakukan komunikasi dua arah dengan para peserta untuk mendiskusikan konsep tersebut, didukung dengan pemutaran video dengan judul "A day made with Glass 2" (Sumber: Youtube), para informan mengakui bahwa mereka menjadi memahami pengertian Era Revolusi Industri 4.0. secara lebih menyeluruh, termasuk kompetensi yang harus dimiliki oleh pendidik dan peserta didik dalam menyongsong era tersebut. Mereka juga menyadari bahwa salah satu kompetensi sentral yang harus dimiliki adalah penguasaan teknologi informasi.

P2.Q2. Saya awalnya nggak tahu apa itu revolusi industri 4.0. tapi setelah pembicara mengajak kami berdiskusi dan nonton video tentang teknologi canggih di masa depan. Saya jadi mengerti, kalau kita harus bisa menguasai teknologi agar tidak ketinggalan dengan bangsa lain. Di video saja nantinya dokter berbeda Negara bisa bekerja sama menyembuhkan pasien. Anak-anak didik juga harus didukung untuk mengetahui penggunaan teknologi, jangan hanya mereka tahu nonton youtube saja.

P5.Q2. Saya baru mengetahui Revolusi Industri 4.0. setelah diminta pembicara mencari melalui google. Ternyata di Jerman sudah ada ya pabrik cerdas, manusia digantikan oleh mesin. Kita benar-benar harus mendidik murid-murid dengan sebaiknya mungkin, sehingga bisa menguasai teknologi. Saya pun sebagai guru harus belajar lagi, terutama saat mengajar mulai lebih intens menggunakan komputer dan internet.

Temuan ini menunjukkan bahwa pentingnya memberikan informasi dan pemahaman kepada guru mengenai gambaran umum Era Revolusi Industri 4.0 Selain untuk meluaskan wawasan guru secara pribadi, pengetahuan ini juga bisa dimanfaatkan untuk mengembangkan kompetensi peserta didik yang dibutuhkan pada era ini (Amin, 2016; Kurnianingsih et al., 2017).

Menambah Pengetahuan Mengenai Fungsi Teknologi dalam Pembelajaran

Sesi selanjutnya materi yang diberikan adalah mengenai sejarah perkembangan teknologi, dan fungsi teknologi dalam pembelajaran. Peneliti 
menemukan bahwa banyak peserta yang masih sangat minim menguasai kemampuan dasar penggunaan komputer dan internet. Begitupun saat peneliti meminta kesediaan peserta untuk menggunakan salah satu perangkat lunak (yakni Microsoft Excel) banyak yang belum menguasainya. Setelah peneliti memberikan materi pada sesi ini, sebagian peserta menyatakan bahwa mereka menjadi mampu mengoperasikan perangkat lunak, dan mengetahui beberapa perangkat lunak lainnya (yakni Geogebra) sehingga bisa menjadi referensi bagi mereka menyusun kegiatan pembelajaran di kelas.

P4.Q3. Saya sudah bisa mengoperasikan Excel, tapi saya baru tahu ada perangkat lain yang namanya geogebra. Luar biasa, kita tidak hanya bisa membuat bangun ruang dari perangkat tersebut tapi juga augmented reality. Saya rasa murid-murid akan sangat fun jika kita bisa memanfaatkan geogebra dalam mata pembelajaran matematika di kelas.

P6.Q3. Saya kurang begitu paham menggunakan Excel dan yang lainnya. Saat pelatihan hanya beberapa tehnik dasar saja, saya rasa perlu ada sesi khusus untuk mempelajari Excel dan juga yang lainnya.

Kemampuan guru menggunakan berbagai perangkat lunak mampu meningkatkan kepercaya dirian guru terhadap pemanfaatan teknologi (Kurnianingsih et al., 2017). Hal ini berimplikasi positif terhadap semakin bervariasinya model pembelajaran yang dilakukan (Ahmadi, 2017; Avidov-Ungar \& Forkosh-Baruch, 2018).

\section{Meningkatkan Objektivitas dalam Memilah Informasi}

Pada hari kedua peneliti memaparkan materi mengenai literasi digital, dimulakan sesi pertama yakni tehnik mencari informasi melalui browser dan memilah milih informasi valid pada laman internet yang dapat dipertanggung jawabkan. Sesi ini diakui oleh peserta menambah sensitifitas mereka dalam mengolah informasi pada laman internet. Peserta semakin menyadari pentingnya menyeleksi home page yang menyiarkan sumber-sumber pengetahuan dan berita.

P1.Q4. Kita seringkali mendapatkan berita/informasi dari berbagai sumber yang tidak diketahui kebenarannya. Dalam pelatihan ini kita jadi tahu media online mana saja yang bisa kita percaya.

P4.Q4. Saya sudah mulai kritis dalam memilah media yang meyebarkan berita karena itu saya pun nggak asal menyebarkan. Namun pelatihan ini membuat saya lebih memahami bagaimana mengkritisi berita dari sisi konten.

Guru perlu memiliki pemahaman mengenai bahayanya mengkonsumsi dan menyebarkan informasi yang tidak valid (a.k.a hoax) dari jaringan online, sehingga sebagai pendidik perlu dapat menyeleksi berita yang diterima sebelum dibagikan 
kepada khalayak khususnya peserta didik. Hal ini merupakan salah satu komponen penting dalam budaya literasi digital bagi pendidik dan peserta didik (Alvermann \& Sanders, 2019; Ranieri, Bruni, \& Kupiainen, 2018).

\section{Memperkaya Sumber Materi Pembelajaran}

Setelah mempelajari bagaimana mengkritisisasi sumber informasi secara umum, selanjutnya ditunjukkan laman-laman sumber materi pembelajaran yang dapat dikunjungi baik yang dimiliki oleh pemerintah maupun yang dimiliki oleh lembaga non-pemerintah. Sebagian besar informan menyatakan bahwa sesi ini menambah daftar sumber materi pengajaran yang bisa mereka kunjungi untuk mendukung proses pembelajaran. Banyak dari informan yang baru mengetahui bahwa pemerintah memiliki laman-laman tidak berbayar yang kaya dengan sumbersumber informasi pembelajaran. Sebagian tertarik untuk mengikuti kuliah daring yang disedikan oleh Universitas Negeri ataupun lembaga non-pemerintah. Namun beberapa diantaranya mengakui kesulitan dalam memahami laman-laman sumber informasi tersebut karena limitasi kompetensi yang dimiliki.

P4.Q5. Saya sangat bersemangat saat pembicara mengenalkan banyak website sumber pembelajaran, terutama yang dimiliki oleh PUSTEKOM dan Khan Academy. Menurut saya menarik sekali jika bisa disampaikan kepada murid-murid.

P3.Q5. Saya tertarik dengan kuliah online yang ditawarkan oleh Universitas Terbuka, pembicara juga bilang kalau kita bisa mendapatkan sertifikat jika mengikuti kuliah tersebut. Bisa menambah sertifikat untuk kepangkatan.

P6.Q5. Banyak sekali sumber informasi yang diberi tahu saat pelatihan, saya tidak ingat semua, kebetulan saya juga kurang bisa mencari informasi menggunakan internet.

Terdapatnya sejumlah sumber materi pembelajaran yang disediakan oleh lembaga pemerintah dan non-pemerintah sesuai dengan jenjang pendidikan. Minimnya sosialisasi akan laman-laman tersebut membuat pihak guru tidak mengetahui keberadaan dan fungsi dari setiap bagian laman. Selain itu rendahnya 'rasa ingin tahu' dan 'kompetensi' yang dimiliki guru terhadap teknologi iformasi membuat mereka bersikukuh dan terbatas pada pengetahuan dan keterampilan yang telah dimiliki (Tondeur, Van Braak, Ertmer, \& Ottenbreit-Leftwich, 2017).

\section{Mengurangi 'kegamangan' menggunakan Teknologi Informasi}

Salah satu tujuan dari penelitian ini adalah, menumbuhkembangkan kepercaya diri peserta ketika berkepentingan menggunakan teknologi. Untuk tujuan ini pelatihan tidak hanya berisi berbagi pengetahuan dalam bentuk slide dan tampilan materi satu arah, tetapi juga disertai praktek langsung, dimana para peserta memanfaatkan teknologi informasi dengan menggunakan laptop pribadi dan bimbingan dari pembicara. Saat peserta menemui kesulitan dalam mengakses laman internet atau hambatan teknis lainnya, pembicara membimbing hingga 
masalah terselesaikan. Pembicara juga mengarahkan peserta yang lebih piawai untuk membantu peserta lain yang mengalami kesulitan, sehingga terjadinya kolaborasi antar peserta.

P2.Q6. Alhamdulillah saat membuka beberapa website tidak ada masalah, hanya saja beberapa kali saya bertanya kepada pembicara beberapa bagian dalam website yang tidak saya pahami. Saya tidak menyangka kalau dipelajari pelan-pelan tidak sesulit yang kita bayangkan.

P7.Q6. Saya sempat membantu guru senior yang kesulitan menemukan website, untuk mereka memang bukan hal gampang. Tapi kalau dipraktekan terus pasti bisa.

Keraguan menggunakan teknologi informasi berkurang saat para guru diberikan pengalaman menggunakan perangkat tersebut secara langsung. Interaksi yang intensif diprediksi semakin menumbuhkan rasa percaya diri guru terhadap ketrampilan mereka memanfaatkan komputer/laptop dan teknologi pendukung. Jika hal ini dilakukan secara berkesinambungan tidak menutup kemungkinan para guru akan menjadi content creator bagi sumber belajar yang mereka gunakan di dalam kelas (Darmaningrat, Ali, Wibowo, \& Astuti, 2018; Dewi, 2015; Sholeh \& Sutanta, 2019).

\section{Pemahaman Literasi Digital Secara Menyeluruh}

Melalui form evaluasi kepada peserta yang berisi beberapa pertanyaan terkait materi yang telah diberikan selama pelatihan, yang mencakup pengertian revolusi industry 4.0 serta penjelasan aplikasi dan laman website sumber pembelajaran, ternyata sebagian besar peserta dapat menjawab pertanyaan dengan sangat baik. Ketika menjawab pertanyaan peserta diijinkan untuk membuka laman internet, namun tetap diminta untuk mengolah jawaban menggunakan kalimat sendiri dan menghindari plagiarisme. Meskipun demikian masih ditemukan beberapa peserta yang melakukan copy-paste jawaban dari laman internet, dengan alasan kurang mampu melakukan paraphase inti kutipan sumber tulisan.

\section{SIMPULAN}

Pelatihan pemanfaatan literasi digital didesain untuk meningkatkan pemahaman dan implementasi literasi digital guru dalam proses pengajaran di sekolah. Serangkaian materi dan praktik teknis dilakukan untuk memperdalam proses berpikir, telaah dan evaluasi guru terhadap sumber informasi yang ditemui di dunia digital. Prosedur ini tidak hanya menambah khasanah pengetahuan guru tapi juga keterampilan mereka dalam memanfaatkan teknologi informasi, dengan demikain kegamangan yang menjadi momok selama ini dapat diminimalisir. Pelatihan ini mempunyai pengaruh positif untuk mempersempit terhapusnya kesenjangan antara literasi digital guru dan kemajuan informasi digital yang cepat. Hal ini diperlukan karena pada dasarnya guru juga mempunyai tanggungjawab 
untuk melatih dan membiasakan murid menggunakan teknologi informasi, supaya siap menjadi warga masyarakat Revolusi Industri 4.0.

\section{REFERENSI}

Ahmadi, F. (2017). Guru SD di Era Digital: Pendekatan, Media, Inovasi. Semarang: CV. Pilar Nusantara.

Alvermann, D. E., \& Sanders, R. K. (2019). Adolescent literacy in a digital world. The international encyclopedia of media literacy, 1-6.

Amin, J. N. (2016). Redefining the role of teachers in the digital era. The International Journal of Indian Psychology, 3(3), 40-45.

Avidov-Ungar, O., \& Forkosh-Baruch, A. (2018). Professional identity of teacher educators in the digital era in light of demands of pedagogical innovation. Teaching and Teacher Education, 73, 183-191.

Bellanca, J. A. (2010). 21st century skills: Rethinking how students learn. USA: Solution Tree Press.

Buckingham, D. (2015). Defining digital literacy-What do young people need to know about digital media? Nordic Journal of Digital Literacy, 10(3), 21-35.

Budiana, H., Sjafirah, N., \& Bakti, I. (2015). Pemanfaatan Teknologi Informasi Dan Komunikasi Dalam Pembelajaran Bagi Para Guru SMPN 2 Kawali Desa Citeureup Kabupaten Ciamis. Dharmakarya: Jurnal Aplikasi Ipteks untuk Masyarakat, 4(1), 59-62.

Darmaningrat, E. W. T., Ali, A. H. N., Wibowo, R. P., \& Astuti, H. M. (2018). Pemanfaatan Aplikasi Digital Learning Untuk Pembelajaran Pengayaan di Sekolah Menengah Kota Surabaya. SESINDO 2018, 2018.

Dewi, F. (2015). Proyek Buku Digital: Upaya Peningkatan Keterampilan Abad 21 Calon Guru Sekolah Dasar Melalui Model Pembelajaran Berbasis Proyek. Metodik Didaktik: Jurnal Pendidikan Ke-SD-An, 9(2), 1-15.

Guemide, B., \& Benachaiba, C. (2012). Exploiting ICT and e-learning in teacher's professional development in Algeria: The case of English secondary school teachers. Turkish Online Journal of Distance Education, 13(3), 33-49.

Huberman, M., \& Miles, M. B. (2002). The qualitative researcher's companion. Thousand Oaks, California: Sage Publication.

Husain, C. (2014). Pemanfaatan teknologi informasi dan komunikasi dalam pembelajaran di SMA Muhammadiyah Tarakan. Jurnal Kebijakan dan Pengembangan Pendidikan, 2(2), 184-192.

Kurnianingsih, I., Rosini, R., \& Ismayati, N. (2017). Upaya Peningkatan Kemampuan Literasi Digital bagi Tenaga Perpustakaan Sekolah dan Guru di Wilayah Jakarta Pusat Melalui Pelatihan Literasi Informasi. Jurnal Pengabdian kepada Masyarakat (Indonesian Journal of Community Engagement), 3(1), 61-76.

Labbas, R., \& Shaban, A. E. (2013). Teacher development in the digital age. Teaching English with technology, 13(3), 53-64.

Mertens, D. M. (2014). Research and evaluation in education and psychology: Integrating diversity with quantitative, qualitative, and mixed methods. Thousand Oaks, California: Sage publications. 
Ranieri, M., Bruni, I., \& Kupiainen, R. P. (2018). Digital and media literacy in teacher education: findings and recommendations from the European Project eMEL. Italian Journal of Educational Research, 11(20), 151-165.

Sholeh, M., \& Sutanta, E. (2019). Pendampingan Pengembangan Bahan Ajar dengan Videoscribe pada Guru Smk Tembarak Temanggung. Jurnal Abdimas BSI: Jurnal Pengabdian Kepada Masyarakat, 2(1), 1-9.

Strauss, A., \& Corbin, J. M. (1997). Grounded theory in practice. San Jose State University, USA: Sage Publication.

Sumantri, B. (2017). Pengaruh Kemampuan, Motivasi dan Semangat Kerja Terhadap Kinerja Guru SMP Negeri di Balongpanggang. e-Jurnal Mitra Pendidikan, 1(7), 789-800.

Sutarsih, T., \& Hasyyati, A. N. (2018). Penggunaan dan Pemanfaatan Teknologi Informasi dan Komunikasi P2TIK Sektor Pendidikan M. Wardhini, E. Sari \& S. Tedjo (Eds.), (pp. 52). Retrieved from https://www.bps.go.id/publication/ 2018/12/24/27971845a9d616341333d103/penggunaan-dan-pemanfaatanteknologi-informasi-dan-komunikasi--p2tik--sektor-pendidikan-2018.html.

Tondeur, J., Van Braak, J., Ertmer, P. A., \& Ottenbreit-Leftwich, A. (2017). Understanding the relationship between teachers' pedagogical beliefs and technology use in education: a systematic review of qualitative evidence. Educational Technology Research and Development, 65(3), 555-575.

Wibowo, E. J. (2013). Media pembelajaran interaktif matematika untuk siswa sekolah dasar kelas IV. Paper presented at the Seruni-Seminar Riset Unggulan Nasional Inoformatika dan Komputer. 